\title{
Electron Tunneling Through Boron Nitride Confirms Marcus-Hush Theory Predictions for Ultramicroelectrodes
}

DOI:

10.1021/acsnano.9b08308

\section{Document Version}

Final published version

Link to publication record in Manchester Research Explorer

\section{Citation for published version (APA):}

Velicky, M., Hu, S., Woods, C., Toth, P., Zolyomi, V., Geim, A., Abruña, H. D., Novoselov, K. S., \& Dryfe, R. (2020). Electron Tunneling Through Boron Nitride Confirms Marcus-Hush Theory Predictions for Ultramicroelectrodes. A C S Nano, 14(1), 993-1002. https://doi.org/10.1021/acsnano.9b08308

\section{Published in:}

A C S Nano

\section{Citing this paper}

Please note that where the full-text provided on Manchester Research Explorer is the Author Accepted Manuscript or Proof version this may differ from the final Published version. If citing, it is advised that you check and use the publisher's definitive version.

\section{General rights}

Copyright and moral rights for the publications made accessible in the Research Explorer are retained by the authors and/or other copyright owners and it is a condition of accessing publications that users recognise and abide by the legal requirements associated with these rights.

\section{Takedown policy}

If you believe that this document breaches copyright please refer to the University of Manchester's Takedown Procedures [http://man.ac.uk/04Y6Bo] or contact uml.scholarlycommunications@manchester.ac.uk providing relevant details, so we can investigate your claim.

\section{OPEN ACCESS}




\title{
Electron Tunneling through Boron Nitride Confirms Marcus-Hush Theory Predictions for Ultramicroelectrodes
}

\author{
Matěj Velicḱ́, ${ }^{*}, \dagger,+, \S \odot$ Sheng Hu, ${ }^{\ddagger}$ Colin R. Woods, ${ }^{\ddagger}$ Péter S. Tóth, ${ }^{\dagger, \perp}$ Viktor Zólyomi, $^{\ddagger}$ Andre K. Geim, ${ }^{\ddagger}$

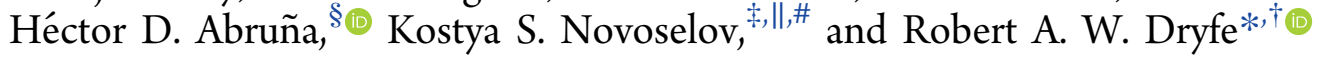 \\ ${ }^{\dagger}$ Department of Chemistry and ${ }^{\ddagger}$ Department of Physics and Astronomy, University of Manchester, Oxford Road, Manchester, M13 \\ 9PL, United Kingdom \\ ${ }^{\S}$ Department of Chemistry and Chemical Biology, Cornell University, Ithaca, New York 14853, United States \\ ${ }^{\perp}$ MTA Premium Post Doctorate Research Program, Department of Physical Chemistry and Materials Science, University of Szeged, \\ Rerrich Square 1, Szeged H-6720, Hungary \\ "Centre for Advanced 2D Materials, National University of Singapore, 117546, Singapore \\ ${ }^{\#}$ Chongqing 2D Materials Institute, Liangjiang New Area, Chongqing, 400714, China
}

\section{Supporting Information}

ABSTRACT: Marcus-Hush theory of electron transfer is one of the pillars of modern electrochemistry with a large body of supporting experimental evidence presented to date. However, some predictions, such as the electrochemical behavior at disk ultramicroelectrodes, remain unverified. Herein, we present a study of electron tunneling across a hexagonal boron nitride acting as a barrier between a graphite electrode and redox mediators in a liquid solution. This was achieved by the fabrication of disk ultramicroelectrodes with a typical diameter of $5 \mu \mathrm{m}$. Analysis of voltammetric measurements, using two common outer-sphere redox mediators, yielded several electrochemical parameters, including the electron transfer rate constant, limiting current, and transfer coefficient. They depart significantly from the Butler-Volmer kinetics and instead show behavior previously predicted by the Marcus-Hush theory of electron transfer. In addition, our system provides a noteworthy experimental platform, which could be applied to address a number of scientific problems such as identification of reaction mechanisms, surface modification, or long-range electron transfer.

KEYWORDS: hBN, electron tunneling, electron transfer, Marcus-Hush theory, microelectrodes
$\mathrm{M}$ arcus-Hush theory has long been recognized as the most successful attempt at developing a comprehensive model of electron transfer kinetics. ${ }^{1,2}$ It describes the electron transfer between reactants and products as a temperature-activated process governed by nuclear vibrations, energy reorganization, and electronic coupling. Several experimental confirmations of this theory have emerged since its inception in the 1950 s, notably the observation of the so-called inverted region for intramolecular electron transfer ${ }^{3}$ and flattening of the exponential dependence of the rate constant on potential for electrode reactions. ${ }^{4}$ However, some intriguing predictions from the Marcus-Hush theory exist, which have not yet been verified experimentally. This includes the theoretical work put forth by Feldberg, who revealed peculiar implications of the Marcus-Hush theory for the steady-state voltammograms at inlaid microdisk electrodes. ${ }^{5}$ Specifically, he predicted a decreasing limiting current at conditions for which the electron transfer became the ratelimiting step, leading to significant deviations from the commonly employed Butler-Volmer model of electrochemical kinetics.

In this work, we achieve such reduction in electron transfer rate by placing layers of hexagonal boron nitride $(\mathrm{hBN})$ of well-defined thickness on a graphite electrode. hBN consists of two-dimensional (2D) layers, in which boron and nitrogen atoms are covalently bound in an alternating hexagonal pattern, similar to graphene. These layers are held together by van der Waals (vdW) forces in bulk hBN. The lattice mismatch between hBN and graphene is only $1.5 \%$, ${ }^{6,7}$ their bulk interlayer spacing is nearly identical (3.3-3.4 $\AA),,^{7,8}$ and

Received: October 22, 2019

Accepted: December 9, 2019

Published: December 9, 2019 
its polar nature renders $\mathrm{hBN}$ insulating, with a wide band gap of $\sim 6 \mathrm{eV} .{ }^{9,10}$ These characteristics lead to an increased carrier mobility in graphene, supported or encapsulated by $\mathrm{hBN}$, owing to the atomic flatness, lack of dangling bonds, and suppression of charge doping at the graphene/hBN interface. ${ }^{11-13}$ It transpires from the present work that $\mathrm{hBN}$ is a suitable medium to study long-range electron tunneling, which leads to the manifestation of the Marcus-Hush behavior.

The quantum tunneling effect is a direct consequence of the Heisenberg uncertainty principle and is most pronounced for light particles, such as electrons, whose de Broglie wavelength is comparable to the tunneling distance. ${ }^{14}$ Initially discovered for trapped electrons, ${ }^{15}$ long-range electron tunneling gradually defined many diverse research fields including scanning tunneling microscopy, molecular electronics, and DNA sequencing. ${ }^{16,17} \mathrm{~A}$ significant body of the electrochemical tunneling studies have involved the following two approaches of modifying conducting electrodes: self-assembled monolayers of redox species tethered to an insulating alkyl chain or insulating films blocking a redox mediator in solution. ${ }^{18}$ The most successful efforts of the latter approach, a strategy chosen in the current work, include electrochemical tunneling through a thermally grown $\mathrm{SiO}_{2}$ layer on $\mathrm{PtSi}^{19,20}$ and a $\omega$-hydroxy thiol layer on $\mathrm{Au}^{21,22}$ both of which have been applied to determine the density of electronic states (DOS) of various redox mediators.

hBN provides an inorganic alternative with a precise control of the tunneling distance, especially within the subnanometer regime, unattainable even for the state-of-the-art tunneling layers of $\mathrm{Al}_{2} \mathrm{O}_{3}$ grown by atomic layer deposition at thicknesses of $\sim 1 \mathrm{~nm} .^{23}$ Additionally, the high crystallinity of $\mathrm{hBN}$ and narrow barrier width ensure scattering-free ballistic electron tunneling and therefore no ohmic heating within the dielectric. ${ }^{17}$ It is therefore not surprising that hBN has been utilized as a tunneling barrier in solid-state devices. This includes hBN being sandwiched between two metals, two graphene/graphite layers, and a metal and graphene. ${ }^{24-28}$ Most of these studies found that the tunneling current increased exponentially with the applied voltage and decayed exponentially with the $\mathrm{hBN}$ thickness to negligible levels for $\sim 6$-layer $\mathrm{hBN}$. Both experiments and theory suggest that $\mathrm{hBN}$ is not simply a passive insulating barrier but rather that it affects the tunneling through carrier interactions with phonons, defects, and dopants. ${ }^{27-29}$

Herein, we employ atomically flat hBN as a tunneling barrier to an electrochemical reaction between a redox mediator in a liquid solution and a graphite electrode (Figure 1). We make use of the electron-beam (e-beam) lithography and poly(methyl methacrylate) (PMMA) mask to fabricate inlaid disk ultramicroelectrodes (Supporting Figure S1) and employ a modified microdroplet electrochemical cell technique described elsewhere. ${ }^{30}$ The use of a high-quality, crystalline $2 \mathrm{D}$ insulator has some advantages over the two traditional tunneling approaches described above, owing to the chemical inertness of hBN, the lack of dangling bonds on its basal plane surface, and a microscopic size of the tunneling area. These characteristics lead to an atomically flat electrode surface, welldefined control of the tunneling distance via the number of hBN layers $(N)$, and significant reduction in the occurrence of pinholes and defects. Additionally, hBN provides a "simple" inorganic tunneling barrier, contrasting with complex organic barriers, which possess discrete molecular energy levels and specific chemical interactions leading to multiple possible
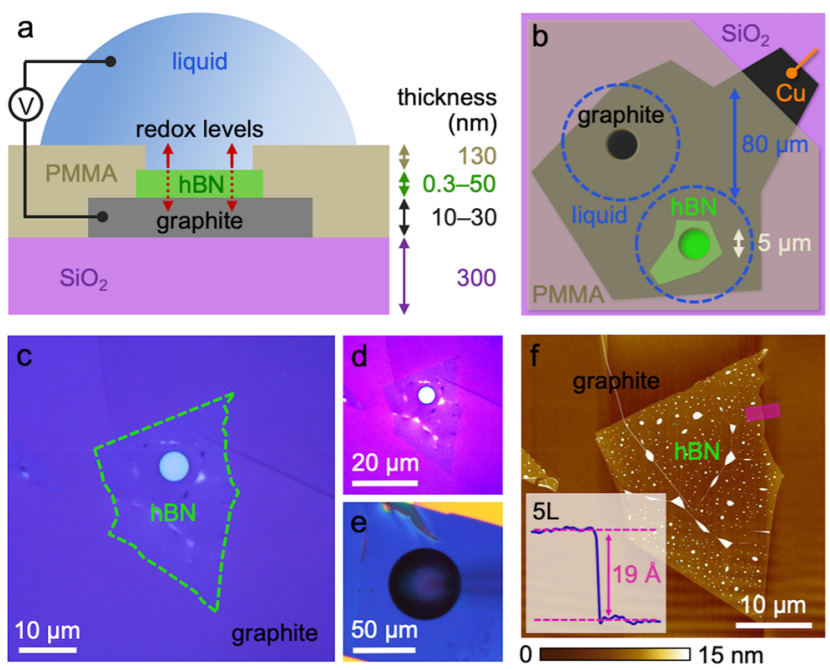

Figure 1. Schematics and characterization of the hBN tunneling devices. (a) Side-view schematic of the liquid/PMMA/hBN/ graphite $/ \mathrm{SiO}_{2}$ heterostructure comprising the tunneling device. (b) Top-view schematic of hBN (green) on graphite (black) coated with PMMA (brown). The openings in the PMMA, exposing both materials, and outlines of liquid microdroplets (blue) are also shown. The schematics are not to scale. (c) Top-view optical image of a 5-layer hBN tunneling device. (d) Same as (c) but in false color and contrast-enhanced. (e) Liquid microdroplet electrochemical cell on the same device, injected by a glass capillary (shadow on the right). (f) AFM characterization of hBN on graphite prior to the e-beam lithography, with the step-edge profile shown in the inset.

configurations. Both redox mediators used here, $\left[\mathrm{IrCl}_{6}\right]^{3-}$ and $\left[\mathrm{Ru}\left(\mathrm{NH}_{3}\right)_{6}\right]^{3+}$, are outer-sphere systems, meaning that they are only sensitive to the DOS of the electrode and not to its surface chemistry. ${ }^{31,32}$ The steady-state voltammograms of $\left[\mathrm{IrCl}_{6}\right]^{3-}$ oxidation and $\left[\mathrm{Ru}\left(\mathrm{NH}_{3}\right)_{6}\right]^{3+}$ reduction in this system exhibit the expected exponential dependence of the tunneling current (and therefore electron transfer rate) on the tunneling distance for monolayer (1L) and bilayer (2L) hBN. However, significant deviations in the measured electrochemical parameters are observed for thicker $\mathrm{hBN}$, which we interpret as a previously predicted, but not yet verified manifestation of the Marcus-Hush theory. ${ }^{5}$ We further rationalize these results based on the density functional theory (DFT) calculations of the energy levels in the graphite/hBN/liquid heterostructure.

\section{RESULTS AND DISCUSSION}

Anatomy of the Tunneling Device. The electron tunneling from (to) the redox mediator in the liquid phase, through hBN of varied thickness, to (from) the graphite electrode was realized using devices depicted in Figure $1 \mathrm{a}, \mathrm{b}$. The basal planes of both graphite and hBN have planar $\mathrm{sp}^{2}$ hybridization, are chemically inert, and lack dangling bonds. Crucially, their surfaces, which face each other in the resulting heterostructure shown in the optical image of Figure 1c,d, are not exposed to any polymer or solvent during the assembly. This ensures that the interface between these two materials is well-defined and atomically flat, and that the tunneling distance between the mediator molecules and graphite can be controlled by the number of hBN layers. In reality, we do observe some contaminants trapped between the hBN and graphite, which favorably agglomerate in micro/nanoscopic pockets visible in atomic force microscopy (AFM) (Figure 1f), 
due to the self-cleaning process occurring at the vdW interfaces. ${ }^{33}$ Importantly, the average height of these pockets is at least $5 \mathrm{~nm}$, leading to a negligible overlap between the electron wave functions of the redox mediator and graphite, ${ }^{17}$ which therefore results in a mere reduction of the apparent tunneling area. The outer-sphere nature of the two redox mediators also ensures that the tunneling process only depends on the DOS and is not sensitive to the chemical groups present at the electrode surface.

Voltammetry of the Electron Tunneling through hBN. The electron tunneling through hBN in the graphite/ $\mathrm{hBN} /$ liquid heterostructure was measured using a microdroplet electrochemical cell shown in Figure 1a and e. The results of the voltammetric (i.e., current-voltage) measurements are summarized in Figure 2. The tunneling process is
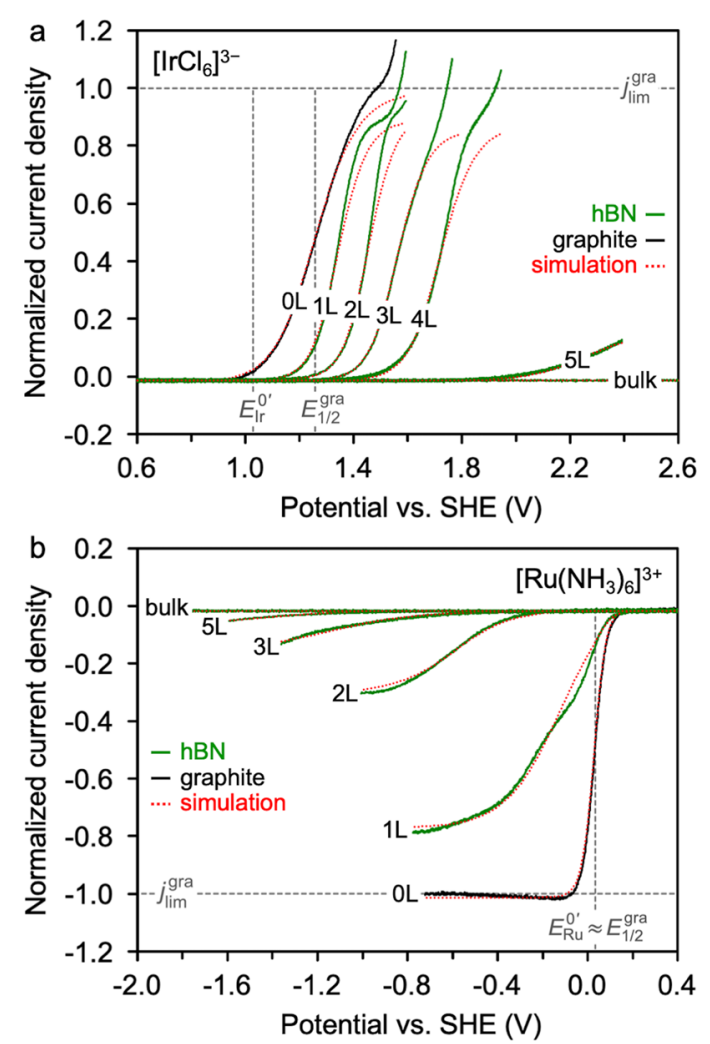

Figure 2. Voltammetry of electron tunneling through hBN. (a, b) Steady-state voltammograms of $\left[\mathrm{IrCl}_{6}\right]^{3-}$ oxidation and $[\mathrm{Ru}-$ $\left.\left(\mathrm{NH}_{3}\right)_{6}\right]^{3+}$ reduction, respectively, on hBN (green curves) and bare graphite (black curves), recorded at a scan rate of $100 \mathrm{mV} \mathrm{s}^{-1}$. The current density is normalized to the limiting current density on bare graphite $(j \mathrm{jim}$ ) $)$. Bulk corresponds to $26 \mathrm{hBN}$ layers $(9 \mathrm{~nm})$. The curves were fitted with an empirical function (red) to obtain the electrochemical parameters, as detailed in Methods.

driven by the difference between the energy (formal potential) of the $\left[\mathrm{IrCl}_{6}\right]^{2-/ 3-}$ or $\left[\mathrm{Ru}\left(\mathrm{NH}_{3}\right)_{6}\right]^{3+/ 2+}$ redox levels $\left(E_{\mathrm{Ir}}^{0 \prime}\right.$ or $\left.E_{\mathrm{Ru}}^{0 \prime}\right)$ in the liquid and the Fermi level $\left(E_{\mathrm{F}}\right)$ of graphite, to which positive or negative potentials are applied $(E)$, respectively. As a result, $\left[\mathrm{IrCl}_{6}\right]^{3-}$ or $\left[\mathrm{Ru}\left(\mathrm{NH}_{3}\right)_{6}\right]^{3+}$ are oxidized or reduced to $\left[\mathrm{IrCl}_{6}\right]^{2-}$ or $\left[\mathrm{Ru}\left(\mathrm{NH}_{3}\right)_{6}\right]^{2+}$ and positive or negative currents are recorded, respectively. Voltammograms on the bare graphite, labeled as $0 \mathrm{~L}$ in Figure 2, were also recorded as a control.

The voltammograms of $\left[\mathrm{IrCl}_{6}\right]^{3-}$ oxidation in Figure 2a exhibit the steady-state sigmoidal shape expected for disk ultramicroelectrodes, for both the bare graphite (black curve) and hBN layers (green curves). Rather than maintaining the limiting value of the potential-independent plateau, however, the current density $(j)$ rises further at large positive potentials, owing to the graphite oxidation side-reaction delimiting the potential window. Importantly, all hBN voltammograms maintain a similar shape to that of the bare graphite, but are offset to increasingly more positive potentials upon increasing $N$. The red curves, fitted to the voltammograms using an empirical function based on the Butler-Volmer formalism, as described in Methods, allowed us to extract the standard heterogeneous electron transfer rate constant $\left(k^{0}\right)$, limiting current density $\left(j_{\text {lim }}\right)$, and transfer coefficient $(\alpha$ or $1-\alpha)$. The $k^{0}$ of $\left[\mathrm{IrCl}_{6}\right]^{3-}$ oxidation on bare graphite averaged over all the devices $\left(\overline{k^{0, \text { gra }}}\right)$ was $(1.4 \pm 0.2) \times 10^{-3} \mathrm{~cm} \mathrm{~s}^{-1}$, about 1 order of magnitude lower than reported previously, ${ }^{34}$ not entirely unexpected considering the exposure of the topmost surface to PMMA during device fabrication.

Interestingly, the partial oxidation of graphite, observed at large positive potentials in voltammograms of Figure 2a, left the consecutive $\left[\mathrm{IrCl}_{6}\right]^{3-}$ voltammograms unaffected, but had notable implications for the subsequent $\left[\mathrm{Ru}\left(\mathrm{NH}_{3}\right)_{6}\right]^{3+}$ voltammetry. The $\left[\mathrm{Ru}\left(\mathrm{NH}_{3}\right)_{6}\right]^{3+}$ reduction voltammograms shown in Figure $2 \mathrm{~b}$ are qualitatively similar to those of $\left[\mathrm{IrCl}_{6}\right]^{3-}$ in that they exhibit the sigmoidal steady-state behavior and the hBN curves occur at increasingly more negative potentials as the $\mathrm{hBN}$ thickness increases. However, the $k^{0}$ values are much higher than expected. Specifically, the $\overline{k^{0, \text { gra }}}$ of $\left[\mathrm{Ru}\left(\mathrm{NH}_{3}\right)_{6}\right]^{3+}$ reduction was $(9.5 \pm 2.0) \times 10^{-2} \mathrm{~cm}$ $\mathrm{s}^{-1}$, which is 3-4 orders of magnitude higher than reported previously $^{34}$ and close to value observed for laser-activated graphite. ${ }^{35}$ This indicates that mild oxidation introduces $\mathrm{sp}^{3}$ disorder in the graphitic lattice and leads to an increase in the DOS near the $E_{\mathrm{F}}$ of unbiased graphite $\left(E_{\mathrm{F}}^{0}\right)$, which lies within $0.05 \mathrm{eV}$ of $E_{\mathrm{Ru}}^{0 \prime} \cdot{ }^{36}$ We recognize that these effects render our analysis semiquantitative, and as such, our main aim is to expose qualitative trends, rather than to obtain absolute values of electrochemical quantities. The evolution of the voltammetric background with $N$ in the pure supporting electrolyte is detailed in Supporting Figure S2.

Dependence of the Electron Transfer Rate on Tunneling Distance. Figure $3 \mathrm{a}$ shows that the measured rate constants $\left(k^{0, \mathrm{hBN}}\right)$ of $\left[\mathrm{IrCl}_{6}\right]^{3-}$ and $\left[\mathrm{Ru}\left(\mathrm{NH}_{3}\right)_{6}\right]^{3+}$, albeit different in absolute value, both decay with the hBN thickness. This is in qualitative agreement with both experiments and predictions for coherent quantum tunneling. ${ }^{16,21,37}$ The exponential dependence of the electron transfer rate constant between an electrode and redox species $\left(k_{\mathrm{ET}}\right.$, in $\left.\mathrm{s}^{-1}\right)$ on the tunneling distance between the two $(x)$ is described as ${ }^{18}$

$$
k_{\mathrm{ET}}(x)=k_{\mathrm{ET}}(0) \mathrm{e}^{-\beta x}
$$

where $k_{\mathrm{ET}}(0)$ and $k_{\mathrm{ET}}(x)$ are the $k_{\mathrm{ET}}$ values at the electrode surface $(x=0)$ and at the distance $x$ from it, respectively, and $\beta$ is the tunneling decay coefficient. Tunneling studies using redox centers tethered to organic molecules (with typical lengths of $5-50 \AA$ ) on metals revealed a $\beta$ of $1.0-1.2 \AA^{-1}$ for alkanethiol chains, ${ }^{37,38} 0.4-0.6 \AA^{-1}$ for $\pi$-conjugated chains, $^{39,40}$ and $0.2-0.3 \AA^{-1}$ for aromatic chains. ${ }^{41-43}$ Tunneling through vacuum between two metals typically yields a $\beta$ of $2.0-2.5 \AA^{-1}$. $^{18}$

Consequently, one could be tempted to perform a linear fit of the data in Figure 3a by adopting eq 1 for $k^{0, \mathrm{hBN}}$. Doing so 

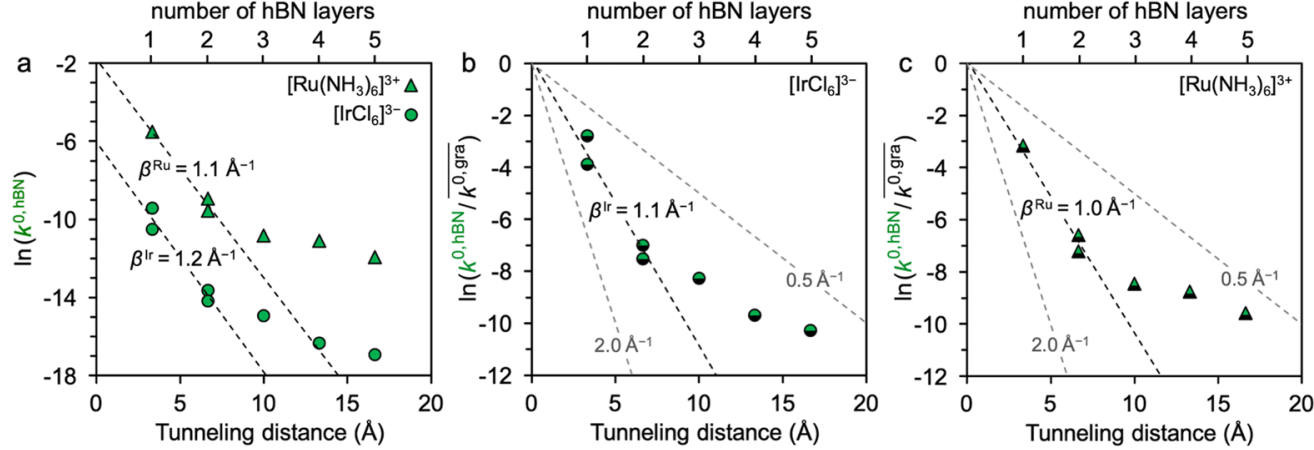

Figure 3. Dependence of the electron transfer rate on tunneling distance. (a) Natural logarithm of the $k^{0}$ on hBN $\left(k^{0, h B N}\right)$ as a function of the tunneling distance for $\left[\mathrm{IrCl}_{6}\right]^{3-}$ (circles) and $\left[\mathrm{Ru}\left(\mathrm{NH}_{3}\right)_{6}\right]^{3+}$ (triangles). The same dependence with $k^{0, \mathrm{hBN}}$ normalized to $\overline{k^{0, \text { gra }}}$ is shown in (b) for $\left[\mathrm{IrCl}_{6}\right]^{3-}$ and in (c) for $\left[\mathrm{Ru}_{(}\left(\mathrm{NH}_{3}\right)_{6}\right]^{3+}$. $\beta$ values are determined from the regression lines fitted to the 1-2L data in (a) and $0-2 \mathrm{~L}$ data in (b) and (c), and equivalent dependencies for $\beta$ of 2.0 and $0.5 \AA^{-1}$ are plotted in (b) and (c) for comparison. The tunneling distance was calculated from $N$ using the theoretical vdW spacing $(3.3 \AA)$ in bulk hBN. ${ }^{8}$

would yield a $\beta$ of $0.4-0.5 \AA^{-1}$, which is somewhat smaller than expected for a wide-band-gap insulator such as hBN. In fact, it is evident from Figure 3a that the distance dependence of $\ln \left(k^{0, \mathrm{hBN}}\right)$ is not linear and decays more slowly as $x$ increases, as seen for $\geq 3 \mathrm{~L} \mathrm{hBN}$. When only $1 \mathrm{~L}$ and $2 \mathrm{~L} h \mathrm{hN}$ are considered for the linear fit, reasonable $\beta$ values of 1.2 and 1.1 $\AA^{-1}$ for $\left[\mathrm{IrCl}_{6}\right]^{3-}$ and $\left[\mathrm{Ru}\left(\mathrm{NH}_{3}\right)_{6}\right]^{3+}$ are obtained. The deviation from eq 1 at large $x$ becomes very apparent when the data are normalized to $\overline{k^{0, \text { gra }}}$, as shown in Figures $3 \mathrm{~b}$ and c. When $0 \mathrm{~L}, 1 \mathrm{~L}$, and $2 \mathrm{~L}$ data are used for the fitting, $\beta$ values of 1.1 and $1.0 \AA^{-1}$ for $\left[\mathrm{IrCl}_{6}\right]^{3-}$ and $\left[\mathrm{Ru}\left(\mathrm{NH}_{3}\right)_{6}\right]^{3+}$ are obtained and the linear fits pass within $\pm 0.2 \AA$ from the origin, as they ought to, since for $x=0 \ln \left(k^{0, \mathrm{hBN}} / \overline{k^{0, \mathrm{gra}}}\right)=\ln (1)=0$. This data normalization also has the noteworthy advantage of canceling out the effects of solvent, electrolyte, and impurity adsorption at the electrode surface.

Let us now review the quantitative aspects of electron transfer formalized by the Marcus-Hush theory. The following formalism for $k_{\mathrm{ET}}$ is usually invoked, describing the electron transfer as a temperature-activated process: ${ }^{44-46}$

$$
k_{\mathrm{ET}}=\nu_{\mathrm{n}} \kappa_{\mathrm{el}} \kappa_{\mathrm{n}}
$$

where $\nu_{\mathrm{n}}$ is the effective nuclear vibration frequency, $\kappa_{\mathrm{el}}$ is the electronic transmission coefficient, and $\kappa_{\mathrm{n}}$ is the nuclear reorganization factor, typically expressed in terms of the standard free energy of activation $\left(\Delta G^{\ddagger}\right):^{18}$

$$
\kappa_{\mathrm{n}}=\mathrm{e}^{-\Delta G^{\ddagger} / k_{\mathrm{B}} T}
$$

where $k_{\mathrm{B}}$ is the Boltzmann constant and $T$ is the temperature. Of all the above quantities, $\kappa_{\mathrm{el}}$ is the only source of the exponential decay with distance:

$$
\kappa_{\mathrm{el}}(x)=\kappa_{\mathrm{el}}(0) \mathrm{e}^{-\beta x}
$$

where $\kappa_{\mathrm{el}}(0)$ and $\kappa_{\mathrm{el}}(x)$ are the $\kappa_{\mathrm{el}}$ values at the electrode surface $(x=0)$ and at a distance $x$ from it, respectively. In the adiabatic regime of strong electronic coupling, $\kappa_{\mathrm{el}}(x) \rightarrow 1$, which manifests itself by the independence of the rate constant on distance. ${ }^{38}$ At larger distances, the electronic coupling weakens, $\kappa_{\mathrm{el}}(x)<1$, and even an initially adiabatic reaction becomes nonadiabatic and independent of the nuclear dynamics since $\kappa_{\mathrm{el}}(x)$ is reduced to ${ }^{44,46,47}$

$$
\kappa_{\mathrm{el}}(x)=\frac{\nu_{\mathrm{el}}^{0}}{\nu_{\mathrm{n}}} \mathrm{e}^{-\beta x}
$$

where $\nu_{\mathrm{el}}^{0}$ is the electron hopping frequency at $x=0$. This quantity is a function of the electrode DOS $\left(\rho_{\mathrm{E}}^{0}\right)$ at energy corresponding to the formal potential $\left(E^{0 \prime}\right)$ of the redox reaction and the electronic coupling matrix between the electrode and redox states $\left(H_{\mathrm{ER}}^{0}\right)$ at $x=0$, according to the Landau-Zener formalism: ${ }^{44,48}$

$$
\nu_{\mathrm{el}}^{0}=\frac{4 \pi^{2} \rho_{\mathrm{E}}^{0}\left(H_{\mathrm{ER}}^{0}\right)^{2}}{h \sqrt{4 \pi \frac{\lambda}{k_{\mathrm{B}} T}}}
$$

where $h$ is the Planck constant and $\lambda$ is the reorganization energy of the redox mediator. Many outer-sphere electrode reactions are nonadiabatic due to weak electronic coupling, which also applies to our system as a result of the low DOS of graphite. ${ }^{36,49}$ The standard heterogeneous electron transfer rate constant $k^{0}$ (in $\mathrm{cm} \mathrm{s}^{-1}$ ) is a special case of $k_{\mathrm{ET}}$ at $E=E^{0 \prime}$, integrated over all the distances from the electrode; so from eq 2 we have

$$
k^{0}=\int_{x=0}^{\infty} k_{\mathrm{ET}}\left(E=E^{0 \prime}\right) \mathrm{d} x=\nu_{\mathrm{n}} \kappa_{\mathrm{n}}\left(E=E^{0 \prime}\right) \int_{\mathrm{x}=0}^{\infty} \kappa_{\mathrm{el}} \mathrm{d} x
$$

Feldberg and Sutin derived an expression for $k^{0}$ for nonadiabatic reactions at electrode surfaces, ${ }^{44}$ which in combination with eq 1 finally yields the distance-dependent $k^{0}$ :

$$
k^{0}(x)=\frac{\nu_{\mathrm{el}}^{0} \pi}{\beta \sqrt{1+\frac{\pi k_{\mathrm{B}} T}{\lambda}}} \mathrm{e}^{-\lambda / 4 k_{\mathrm{B}} T} \mathrm{e}^{-\beta x}
$$

When the coherent quantum tunneling arises solely from the electronic coupling between the electrode and the redox mediator, then $\beta$ exclusively describes the tunneling decay and is independent of potential and temperature, and its reciprocal value has the physical meaning of a reaction zone thickness. ${ }^{45}$

Equation 8 provides the means to estimate $\nu_{\mathrm{el}}^{0}$ from the intercepts in Figure 3a. Using an arbitrary value of $\lambda=1.0 \mathrm{eV}$ for both mediators ${ }^{50}$ yields a $\nu_{\mathrm{el}}^{0}$ of $6.8 \times 10^{7}$ and $2.3 \times 10^{11} \mathrm{~s}^{-1}$ for $\left[\mathrm{IrCl}_{6}\right]^{3-}$ and $\left[\mathrm{Ru}\left(\mathrm{NH}_{3}\right)_{6}\right]^{3+}$, respectively. We then use these $\nu_{\mathrm{el}}^{0}$ values and eq 6 to calculate $\rho_{\mathrm{E}}^{0}$ at $x=0$, i.e., the DOS of bare graphite (using $H_{\mathrm{ER}}^{0} \approx 0.1 \mathrm{eV}$ ). ${ }^{44}$ The $\rho_{\mathrm{E}}^{0}$ of $1.6 \times 10^{-5}$ atom ${ }^{-1} \mathrm{eV}^{-1}$ for $\left[\mathrm{IrCl}_{6}\right]^{3-}$ is in agreement with reported values 
for the basal plane graphite, while the $\rho_{\mathrm{E}}^{0}$ of $5.4 \times 10^{-4}$ atom $^{-1}$ $\mathrm{eV}^{-1}$ for $\left[\mathrm{Ru}\left(\mathrm{NH}_{3}\right)_{6}\right]^{3+}$ is closer to the edge plane graphite, consistent with the above discussion. ${ }^{36}$

Manifestation of the Marcus-Hush Theory of Electron Transfer. We observe further anomalies in the other two electrochemical parameters determined from the voltammetric fitting, namely, the transfer coefficient and limiting current density, which are plotted in Figure 4 as a
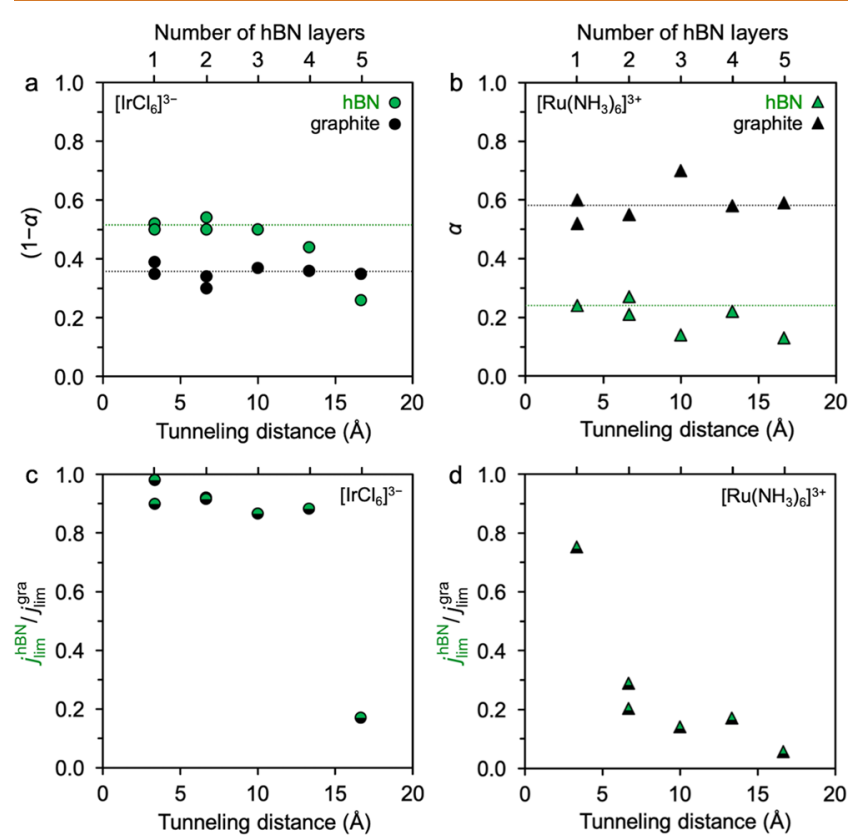

Figure 4. Dependence of the transfer coefficient and limiting current density on tunneling distance. $(\mathrm{a}, \mathrm{b})(1-\alpha)$ and $\alpha$ as a function of the tunneling distance for $\left[\mathrm{IrCl}_{6}\right]^{3-}$ and $\left[\mathrm{Ru}\left(\mathrm{NH}_{3}\right)_{6}\right]^{3+}$, respectively. Green marks correspond to $\mathrm{hBN}$; black marks to bare graphite. (c, d) Limiting current density on hBN ( $\left.\mathrm{j}_{\lim }^{\mathrm{hBN}}\right)$ as a function of the tunneling distance for $\left[\mathrm{IrCl}_{6}\right]^{3-}$ and $\left[\mathrm{Ru}\left(\mathrm{NH}_{3}\right)_{6}\right]^{3+}$, respectively, normalized to $j_{\text {lim }}^{\text {gra }}$.

function of the tunneling distance. Figure $4 \mathrm{a}$ and $\mathrm{b}$ show that bare graphite yields an average $(1-\alpha)$ of 0.36 for $\left[\mathrm{IrCl}_{6}\right]^{3-}$ and average $\alpha$ of 0.58 for $\left[\mathrm{Ru}\left(\mathrm{NH}_{3}\right)_{6}\right]^{3+}$, both of which are reasonable values, indicating a high symmetry of the reduction/oxidation reactions. ${ }^{18}$ However, a progressive decrease of an initially constant $(1-\alpha)$ of 0.51 is observed for $\left[\mathrm{IrCl}_{6}\right]^{3-}$ oxidation for $>3 \mathrm{~L} \mathrm{hBN}$. $\left[\mathrm{Ru}\left(\mathrm{NH}_{3}\right)_{6}\right]^{3+}$ reduction on hBN does not exhibit as clear a decrease in $\alpha$ with the tunneling distance but yields unusually small values of $\alpha$ between 0.13 and 0.27 . Another striking observation shown in Figure $4 \mathrm{c}$ and $\mathrm{d}$ is that the $j_{\lim }$ on $\mathrm{hBN}\left(j_{\lim }^{\mathrm{hbn}}\right)$, normalized to $j_{\mathrm{lim}}^{\mathrm{gra}}$ does not reach the expected unity maximum at large potentials and instead decreases progressively with increasing tunneling distance. This is true for $\left[\mathrm{IrCl}_{6}\right]^{3-}$ on $5 \mathrm{~L} \mathrm{hBN}$ and for $\left[\mathrm{Ru}\left(\mathrm{NH}_{3}\right)_{6}\right]^{3+}$ on all hBN thicknesses. The small $<15 \%$ decrease of $j_{\text {lim }}^{\mathrm{hBN}} / j_{\text {lim }}^{\mathrm{gra}}$ from unity for $\left[\mathrm{IrCl}_{6}\right]^{3-}$ on $1-4 \mathrm{~L} \mathrm{hBN}$ can be attributed to the previously discussed contamination at the $\mathrm{hBN} /$ graphite interface.

Such anomalous behavior of $j_{\lim }$ and $\alpha($ or $1-\alpha)$ indicates a departure from the Butler-Volmer model of electrochemical kinetics, which was used to analyze the data. In a predictive theoretical study, Feldberg showed that, under certain conditions, the steady-state voltammograms on disk ultramicroelectrodes deviate from the Butler-Volmer behavior and instead follow the Marcus-Hush theory. ${ }^{5}$ Crucially, the Butler-Volmer model continues to produce a good voltammetric fit, but $k^{0}$ and $\alpha$ (or $1-\alpha$ ) become mere fitting parameters. Consequently, their apparent values increase and decrease, respectively, and the physical value of $j_{\text {lim }}$ decreases as Marcus-Hush behavior dominates, much in agreement with our observations. The qualitative conditions necessary to observe these anomalies were identified as large overpotentials, small $k^{0}$, small electrode size, and small $\lambda$ (i.e., a "fast" redox system). Feldberg argued that such conditions would be difficult to achieve simultaneously in an experiment; ${ }^{5}$ however, our system favorably meets all of these conditions. For $\lambda=1.0$ $\mathrm{eV}$, the two kinetics models are only distinguishable when $I E-$ $E^{0 \prime} \mid \geq 0.5 \mathrm{~V}$ (easily accessible in our system), and $99 \%$ of the Marcus-Hush potential-independent $k^{0}$ plateau is reached when $\left|E-E^{0 \prime}\right| \geq 1.5 \mathrm{~V}$. $^{5}$ Furthermore, the following distinguishability condition must be met:

$$
\frac{k^{0} r}{D} \leq 10^{\left(1-\lambda / 10 k_{\mathrm{B}} T\right)}
$$

where $r$ is the electrode radius and $D$ is the diffusion coefficient of the redox mediator. One way to approach this condition is to decrease $r$ to units of nanometers, a feat demonstrated more than a decade ago; ${ }^{51}$ however, this leads to complications as $r$ becomes comparable to the electrical double-layer thickness found at typical aqueous electrolyte concentrations. Basal plane graphite has long been identified as having small $k^{0}$ for outersphere redox mediators due to its low DOS, but little effort has been expended toward employing it as an ultramicroelectrode. More crucially, very few systems have values of $k^{0}$ and $\lambda$ low enough to meet the conditions imposed by eq 9 , since $k^{0}$ increases with decreasing $\lambda$, according to eq 8 . Our system is noteworthy, since $\lambda$ is kept constant, whereas the apparent $k^{0}$ decreases progressively with the tunneling distance due to the weakened electronic coupling. Consequently, the combination of the basal plane graphite ultramicroelectrodes with $r=2.5$ $\mu \mathrm{m}$ and tunneling through $\mathrm{hBN}$, which pushes the apparent $k^{0}$ to below $10^{-7}-10^{-5} \mathrm{~cm} \mathrm{~s}^{-1}$, allows the conditions imposed by eq 9 to be met, subject to the value of $\lambda$. In fact, we can obtain a rough estimate of $\lambda$, based on the observed deviation from the expected exponential decay between 2-3L hBN layers (Figure 3). Evaluating $k^{0}, r$, and $D$ values against eq 9 thus leads to $\lambda \approx 1.3 \mathrm{eV}$ for $\left[\mathrm{IrCl}_{6}\right]^{3-}$ and $\lambda \approx 0.7 \mathrm{eV}$ for $\left[\mathrm{Ru}\left(\mathrm{NH}_{3}\right)_{6}\right]^{3+}$, both in agreement with experimentally determined values of $\sim 1.2 \mathrm{eV}^{52}$ and $\sim 0.6 \mathrm{eV},{ }^{22}$ respectively, though in disagreement with some theoretical predictions. ${ }^{50}$ This also explains why deviations in $\alpha$ and $j_{\text {lim }}$ are only seen at the largest distances for $\left[\mathrm{IrCl}_{6}\right]^{3-}$, while anomalous behavior is observed for $\left[\mathrm{Ru}\left(\mathrm{NH}_{3}\right)_{6}\right]^{3+}$ across the entire range of distances. We stress that the above evaluation is very approximate and does not fully explain all the aspects of the observed deviations. However, we believe the above data provide a robust qualitative evidence for the yet unverified Feldberg's predictions and importantly afford another experimental confirmation of one of the most important treatments of electron transfer: the Marcus-Hush theory.

Properties of the hBN Tunneling Barrier. It is instructive to consider the properties of the tunneling barrier and its dependence on the $\mathrm{hBN}$ thickness and applied potential. The band diagram in Figure 5a schematically depicts the various energy levels in the graphite/1L hBN/liquid heterostructure and their mutual alignment for the unbiased case prior to contact between the three phases. In reality, the 

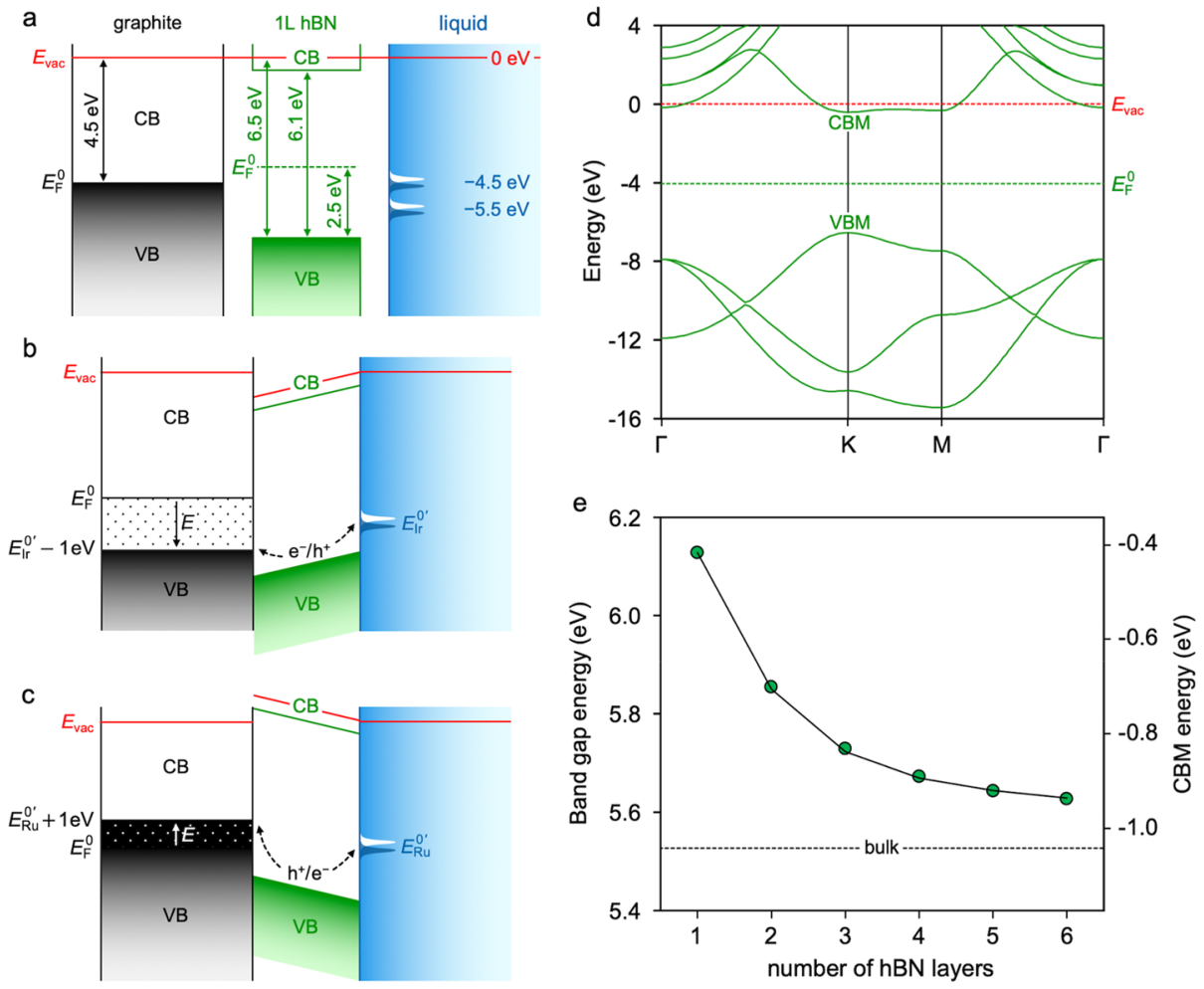

Figure 5. Band structure and alignment of the hBN tunneling barrier. (a) Band diagram of the different energy levels within the graphite, 1L $\mathrm{hBN}$, and liquid, prior to their contact. (b, c) Band diagrams of the energy level alignment in the biased graphite/1L hBN/liquid heterostructure for the $\left[\mathrm{IrCl}_{6}\right]^{3-}$ oxidation $(\mathrm{b})$ and $\left[\mathrm{Ru}\left(\mathrm{NH}_{3}\right)_{6}\right]^{3+}$ reduction $(\mathrm{c})$. (d) Electronic band structure of $1 \mathrm{~L}$ hBN. (e) Evolution of the band gap (circles) and CBM (solid line) on the number of hBN layers. The band gap of bulk hBN, extrapolated from a reciprocal dependence on $N$, is also shown. Graphite and hBN energy levels and band structures have been calculated using DFT, except for the $E_{\mathrm{F}}^{0}$ of hBN, which was taken from ref 53 . The redox energy levels were measured experimentally and converted to the vacuum scale $\left(E_{\mathrm{vac}}=0 \mathrm{eV}\right){ }^{54}$

internal structure of the tunneling barrier is likely to be more complex, due to the high anisotropy of hBN. Figure $5 \mathrm{~b}$ shows the tunneling process for the $\left[\mathrm{IrCl}_{6}\right]^{3-}$ oxidation, with a large positive potential applied to the graphite, allowing the electrons to tunnel from the occupied states of $\left[\mathrm{IrCl}_{6}\right]^{3-}$ to the empty states in graphite. Similarly, Figure 5c shows the electron tunneling from the occupied states in graphite to the empty states of $\left[\mathrm{Ru}\left(\mathrm{NH}_{3}\right)_{6}\right]^{3+}$, facilitated by the large negative potential applied to the graphite. An important implication of the analysis in Figures $5 \mathrm{a}-\mathrm{c}$ is that both processes are dominated by the electron/hole tunneling near the valence band maximum (VBM), rather than the conduction band minimum (CBM), of $\mathrm{hBN}$, since this path has a significantly lower tunneling barrier. Furthermore, the barrier for tunneling to/from $\left[\mathrm{IrCl}_{6}\right]^{3-}$ is smaller than that for $\left[\mathrm{Ru}\left(\mathrm{NH}_{3}\right)_{6}\right]^{3+}$ thanks to the relative position of the redox levels and VBM of hBN.

The dependence of the electronic band structure, shown in Figure $5 \mathrm{~d}$ for $1 \mathrm{~L}$, on the number of $\mathrm{hBN}$ layers is also an important consideration, given the nature of the present study. While little experimental information has so far been offered on this matter, our DFT calculations reveal a strong dependence of the band gap energy on the number of hBN layers, changing from $6.1 \mathrm{eV}$ for $1 \mathrm{~L}$ to $5.6 \mathrm{eV}$ for $6 \mathrm{~L}$, as shown in Figure 5e. However, this $\sim 0.5 \mathrm{eV}$ difference originates from the decrease in the CBM, with the VBM remaining nearly constant. As discussed above, the tunneling occurs via the VBM (rather than the CBM) route for both mediators, and therefore we do not expect the $\mathrm{hBN}$ band gap dependence to affect the tunneling processes here.
We also evaluated the distribution of the applied potential across the graphite/hBN/liquid heterostructure. Figure 6a
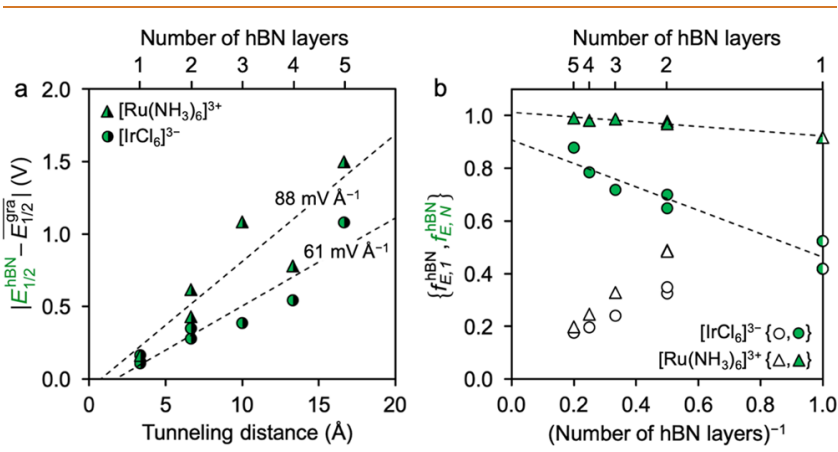

Figure 6. Applied potential and its distribution across the hBN tunneling barrier. (a) Absolute difference between $E_{1 / 2}^{\mathrm{hBN}}$ and $\overline{E_{1 / 2}^{\text {gra }}}$ as a function of the tunneling distance for both mediators. (b) Fraction of the applied potential spent within the hBN tunneling barrier for both mediators. Both absolute values (green markers) and values normalized to the hBN thickness (empty markers) are shown.

shows the difference between the hBN and graphite half-wave potentials ( $E_{1 / 2}^{\mathrm{hBN}}$ and $\overline{E_{1 / 2}^{\mathrm{gra}}}$, respectively) as a function of the hBN thickness. This difference can be thought of as the additional voltage (akin to an overpotential) that has to be applied, with the hBN barrier present, in order to achieve the same current density as that obtained on bare graphite. We further express this quantity as the fraction of the applied 
potential "spent" within the $\mathrm{hBN}$, according to the following expression:

$$
f_{E, 1}^{\mathrm{hBN}}=\frac{1}{N} f_{E, N}^{\mathrm{hBN}}=\frac{1}{N} \frac{\left|E_{1 / 2}^{\mathrm{hBN}}-\overline{E_{1 / 2}^{\mathrm{gra}}}\right|}{\left|E_{1 / 2}^{\mathrm{hBN}}-E^{0 \prime}\right|}
$$

where $f_{E, 1}^{\mathrm{hBN}}$ and $f_{E, N}^{\mathrm{hBN}}$ are the fractions of $E$ spent per hBN layer and in $N$ layers of hBN, respectively. Figure $6 \mathrm{~b}$ shows these fractions as a function of the inverse hBN thickness and, as expected, suggests that, for large $N, f_{E, N}^{\mathrm{hBN}}$ approaches unity for both mediators. However, it also shows that less of $E$ is spent in $\mathrm{hBN}$ for $\left[\mathrm{IrCl}_{6}\right]^{3-}$ in comparison to $\left[\mathrm{Ru}\left(\mathrm{NH}_{3}\right)_{6}\right]^{3+}$. This indicates a smaller tunneling barrier for the former, at least for the few-layer hBN measured here, which is in agreement with the differences predicted from Figure 5b,c.

It is not unlikely that the tunneling transport through $\mathrm{hBN}$ is affected by impurity- or defect-induced midgap states, as predicted for an hBN/graphene heterostructure ${ }^{29}$ and evidenced by the slight p-doping in bulk hBN. ${ }^{53}$ Impurities usually average less than $10^{18} \mathrm{~cm}^{-3}$ in good-quality $\mathrm{hBN},{ }^{55}$ which can be exceeded locally. ${ }^{56}$ Our own measurements of bulk $\mathrm{hBN}$ and hBN/graphite heterostructure by X-ray photoelectron spectroscopy (XPS) and Raman spectroscopy, respectively, did not reveal any additional peaks or shoulders in the relevant spectral regions, suggesting that the defect/ impurity concentrations are low (Supporting Figure S3). Furthermore, the dielectric breakdown measurements yielded a high dielectric strength of $\sim 2 \mathrm{~V} \mathrm{~nm}^{-1}$ (Supporting Figure S4), in agreement with previous reports. ${ }^{24-26}$

\section{CONCLUSIONS}

We studied electron tunneling across an atomically flat hBN barrier sandwiched between a graphite electrode and two outer-sphere redox mediators in a liquid solution. The steadystate voltammetry of $\left[\mathrm{IrCl}_{6}\right]^{3-}$ oxidation and $\left[\mathrm{Ru}\left(\mathrm{NH}_{3}\right)_{6}\right]^{3+}$ reduction obtained on disk ultramicroelectrodes with typical diameters of $5 \mu \mathrm{m}$ revealed an exponential dependence of the apparent electron transfer rates on the $\mathrm{hBN}$ thickness for $1 \mathrm{~L}$ and $2 \mathrm{~L} h B N$. For thicker hBN, deviations in $k^{0}, j_{\lim }$, and $\alpha(1-$ $\alpha$ ) were observed, indicating limitations of the Butler-Volmer model of electrochemical kinetics. This behavior is qualitatively consistent with thus far unverified predictions from MarcusHush theory for disk ultramicroelectrodes and, as such, provides further confirmatory evidence for one of the most fundamental treatments of electron transfer. Furthermore, the experimental platform developed here could be exploited in a range of diverse scenarios, including studies of long-range electron transfer, electrochemical switching between outer- and inner-sphere reactions, and investigation of electrocatalytic mechanisms. It could be possible to discriminate between outer-sphere and inner-sphere reactions as recently shown for $1 \mathrm{~L} \mathrm{MoS}_{2}$ on $\mathrm{Au},{ }^{57}$ explore electrocatalytic reactions on $\mathrm{hBN} /$ metal heterostructures, ${ }^{58,59}$ and study proton tunneling/ transport through $1 \mathrm{~L} \mathrm{hBN.}{ }^{60}$ Such developments are even more likely to succeed, once a reliable control over the thickness and quality of synthetically grown, large-area $\mathrm{hBN}$ is established. $^{61}$

\section{METHODS}

Device Fabrication and Characterization. The tunneling devices were prepared by mechanical exfoliation of graphite (NGS Naturgraphit) and hBN (hq graphene), dry stamp-transfer, and ebeam lithography (Zeiss EVO), as described in Supporting Figure S1.
Briefly, graphite was exfoliated to $c a .10-30 \mathrm{~nm}$ thickness onto a 300 $\mathrm{nm} \mathrm{SiO}_{2} / \mathrm{Si}$ substrate. hBN was exfoliated onto a PMMA substrate and then placed on the graphite using the stamp-transfer method. ${ }^{62}$ The resulting hBN/graphite heterostructure was spin-coated with an insulating PMMA layer (130 nm thick), in which two identical circular working electrode openings (typically $5 \mu \mathrm{m}$ in diameter) over the basal planes of bare graphite and hBN were created using e-beam lithography (Figure 1a,b). Electrical contact was made by scratchexposing the graphite away from the openings and bonding it to a $\mathrm{Cu}$ wire using Ag paint. A Nikon Eclipse LV100ND optical microscope and a DS-Fi2 U3 CCD camera (Nikon Metrology, UK Ltd.) were employed to acquire the optical images (Figure 1c,d). The electrochemical cell was formed by dispensing a microdroplet of a liquid solution (typically $60-100 \mu \mathrm{m}$ in diameter) around the opening (Figure 1e). The number of hBN layers was determined by a Bruker Dimension 3100 V AFM in tapping mode (Figure 1f). Raman spectra were collected using an inVia spectrometer (Renishaw) with a $532 \mathrm{~nm}$ laser excitation, and XPS was measured using a Thermo Scientific Al K-Alpha Theta Probe.

Electrochemical Measurements. All electrochemical measurements were performed in $6 \mathrm{M} \mathrm{LiCl}$ supporting electrolyte aqueous solution, which minimized the evaporation of the liquid. Dispensation and manipulation of the microdroplets on the surface were controlled using a pneumatic microinjector and a micromanipulator reported previously. ${ }^{30,63}$ The potential was applied to the graphite electrode using a PGSTAT302N potentiostat (Metrohm Autolab), and a scan rate of $100 \mathrm{mV} \mathrm{s}^{-1}$ was used in order to achieve a steady-state ultramicroelectrode response without the thin-layer cell diffusional effects (Supporting Figure S5). The $k^{0}, j_{\text {lim }}$, and $\alpha$ (or $1-\alpha$ ) were determined by fitting the voltammograms with the following empirical function based on a Butler-Volmer model of the electrochemical kinetics:

$$
\theta \frac{j}{j_{\lim }}=\left[1+\frac{\pi}{\kappa \theta}\left(\frac{2 \kappa \theta+3 \pi}{4 \kappa \theta+3 \pi^{2}}\right)\right]^{-1}
$$

where $\theta$ and $\kappa$ are defined as follows (for the reduction and oxidation, respectively):

$$
\begin{aligned}
& \theta=1+\frac{D_{\mathrm{O}}}{D_{\mathrm{R}}} \mathrm{e}^{F / R T\left(E-E^{0 \prime}\right)} \text { and } \theta=1+\frac{D_{\mathrm{R}}}{D_{\mathrm{O}}} \mathrm{e}^{-F / R T\left(E-E^{0 \prime}\right)} \\
& \kappa=\frac{\pi k^{0} r}{4 D_{\mathrm{O}}} \mathrm{e}^{-\alpha F / R T\left(E-E^{0 \prime}\right)} \text { and } \kappa=\frac{\pi k^{0} r}{4 D_{\mathrm{R}}} \mathrm{e}^{(1-\alpha) F / R T\left(E-E^{0 \prime}\right)}
\end{aligned}
$$

where $D_{\mathrm{O}}$ and $D_{\mathrm{R}}$ are the diffusion coefficients of the oxidized and reduced form of the mediator, respectively, $F$ is the Faraday constant, $R$ is the universal gas constant, and all other symbols have the same meaning as defined previously. Equations 11-13, which had been introduced by Oldham and Zoski, ${ }^{64}$ were used by Feldberg to model the Butler-Volmer behavior at disk ultramicroelectrodes. ${ }^{5}$ The $D_{\mathrm{O}}$ $\left(D_{\mathrm{R}}\right)$ values of $2.5(2.2) \times 10^{-6} \mathrm{~cm}^{2} \mathrm{~s}^{-1}$ for $\left[\mathrm{Ru}\left(\mathrm{NH}_{3}\right)_{6}\right]^{3+/ 2+}$ and 2.4 $(2.1) \times 10^{-6} \mathrm{~cm}^{2} \mathrm{~s}^{-1}$ for $\left[\mathrm{IrCl}_{6}\right]^{2-/ 3-}$ were determined as averages from cyclic voltammetric and chronoamperometric measurements at a Pt disk electrode ( $1.1 \mathrm{~mm}$ radius), using the Randles-Sevčík and Cottrell equations, respectively. ${ }^{18}$ The $E^{0}$ s of $\left[\mathrm{Ru}\left(\mathrm{NH}_{3}\right)_{6}\right]^{3+/ 2+}$ and $\left[\mathrm{IrCl}_{6}\right]^{2-/ 3-}$ reduction/oxidation were determined from cyclic voltammetry using the same electrode. The potential, measured against a $\mathrm{Ag} / \mathrm{AgCl}$ reference electrode, was converted to the standard hydrogen electrode (SHE) scale. A large-area Pt counter electrode was used to complete the three-electrode configuration. All measurements were carried out at ambient temperature $\left(20-25{ }^{\circ} \mathrm{C}\right)$.

DFT Calculations. Theoretical calculations were performed using the VASP $\operatorname{code}^{65}$ in a plane-wave basis. Bulk graphite was approximated with a 6L-thick slab. We used a plane-wave cutoff energy of $600 \mathrm{eV}$ throughout and left at least $20 \AA$ of vacuum space above the $2 \mathrm{D}$ sheets in order to model isolated materials. The $k$-point grid was set to a $\Gamma$-centered $12 \times 12 \times 1$ Monkhorst-Pack grid. The local density approximation was used to compute the band structures, ionization energies, and hBN band gaps. A correction to the latter 
quantities was necessary as both of them are underestimated in semilocal DFT. ${ }^{66}$ The scissor correction to the band gap and correction to the ionization energy were obtained by recalculating these quantities in the few-layer $(\leq 3 \mathrm{~L})$ limit of $\mathrm{hBN}$ using the HSE06 functional. ${ }^{67}$ We found no dependence of either correction on $N$ and therefore assume that it can be applied to all hBN thicknesses.

\section{ASSOCIATED CONTENT}

\section{S Supporting Information}

The Supporting Information is available free of charge at https://pubs.acs.org/doi/10.1021/acsnano.9b08308.

Tunneling device fabrication; voltammetry in pure supporting electrolyte; Raman spectroscopy and XPS of $\mathrm{hBN}$ and graphite; dielectric breakdown estimation; $\left[\mathrm{IrCl}_{6}\right]^{2-/ 3-}$ voltammetry on graphite at varied scan rates (PDF)

\section{AUTHOR INFORMATION}

\section{Corresponding Authors}

*E-mail: matej.velicky@manchester.ac.uk.

*E-mail: robert.dryfe@manchester.ac.uk.

\section{ORCID}

Matěj Velický: 0000-0003-4230-3811

Héctor D. Abruña: 0000-0002-3948-356X

Robert A. W. Dryfe: 0000-0002-9335-4451

Notes

The authors declare no competing financial interest.

\section{ACKNOWLEDGMENTS}

This project has received funding from the UK EPSRC (grant no. EP/K016954/1) and the European Union's Horizon 2020 research and innovation program under the Marie SkłodowskaCurie grant agreement no. 746685. V.Z. thanks the Graphene Flagship Project and the Computational Shared Facility at the University of Manchester for support. P.S.T. thanks the Hungarian Academy of Sciences for an MTA Premium Post Doctorate Research Program Grant (461029). We also thank S. Feldberg, D. Muller, and P. McEuen and his group for invaluable discussions about this work.

\section{REFERENCES}

(1) Hush, N. S. Adiabatic Theory of Outer Sphere Electron-Transfer Reactions in Solution. Trans. Faraday Soc. 1961, 57, 557-580.

(2) Marcus, R. A. Chemical and Electrochemical Electron-Transfer Theory. Annu. Rev. Phys. Chem. 1964, 15, 155-196.

(3) Miller, J. R.; Calcaterra, L. T.; Closs, G. L. Intramolecular LongDistance Electron Transfer in Radical Anions. The Effects of Free Energy and Solvent on the Reaction Rates. J. Am. Chem. Soc. 1984, 106, 3047-3049.

(4) Chidsey, C. E. D. Free Energy and Temperature Dependence of Electron Transfer at the Metal-Electrolyte Interface. Science 1991, 251, 919-922.

(5) Feldberg, S. W. Implications of Marcus-Hush Theory for Steady-State Heterogeneous Electron Transfer at an Inlaid Disk Electrode. Anal. Chem. 2010, 82, 5176-5183.

(6) Xu, Y.-N.; Ching, W. Y. Calculation of Ground-State and Optical Properties of Boron Nitrides in the Hexagonal, Cubic, and Wurtzite Structures. Phys. Rev. B: Condens. Matter Mater. Phys. 1991, 44, 77877798.

(7) Slonczewski, J. C.; Weiss, P. R. Band Structure of Graphite. Phys. Rev. 1958, 109, 272-279.

(8) Hod, O. Graphite and Hexagonal Boron-Nitride Have the Same Interlayer Distance. Why? J. Chem. Theory Comput. 2012, 8, 13601369.
(9) Watanabe, K.; Taniguchi, T.; Kanda, H. Direct-Bandgap Properties and Evidence for Ultraviolet Lasing of Hexagonal Boron Nitride Single Crystal. Nat. Mater. 2004, 3, 404-409.

(10) Cassabois, G.; Valvin, P.; Gil, B. Hexagonal Boron Nitride Is an Indirect Bandgap Semiconductor. Nat. Photonics 2016, 10, 262-266.

(11) Mayorov, A. S.; Gorbachev, R. V.; Morozov, S. V.; Britnell, L.; Jalil, R.; Ponomarenko, L. A.; Blake, P.; Novoselov, K. S.; Watanabe, K.; Taniguchi, T.; Geim, A. K. Micrometer-Scale Ballistic Transport in Encapsulated Graphene at Room Temperature. Nano Lett. 2011, 11, 2396-2399.

(12) Ahn, G.; Kim, H. R.; Ko, T. Y.; Choi, K.; Watanabe, K.; Taniguchi, T.; Hong, B. H.; Ryu, S. Optical Probing of the Electronic Interaction between Graphene and Hexagonal Boron Nitride. ACS Nano 2013, 7, 1533-1541.

(13) Dean, C. R.; Young, A. F.; Meric, I.; Lee, C.; Wang, L.; Sorgenfrei, S.; Watanabe, K.; Taniguchi, T.; Kim, P.; Shepard, K. L.; Hone, J. Boron Nitride Substrates for High-Quality Graphene Electronics. Nat. Nanotechnol. 2010, 5, 722-726.

(14) Bell, R. P. The Tunnel Effect in Chemistry; Chapman and Hall: London, 1980; p 222.

(15) Compton, R. G. Electron Tunneling in Chemistry: Chemical Reaction over Large Distances, 1st ed.; Elsevier: Amsterdam, 1989; Vol. 30, p 358.

(16) Albrecht, T. Electrochemical Tunnelling Sensors and Their Potential Applications. Nat. Commun. 2012, 3, 829.

(17) McCreery, R. L.; Yan, H.; Bergren, A. J. A Critical Perspective on Molecular Electronic Junctions: There Is Plenty of Room in the Middle. Phys. Chem. Chem. Phys. 2013, 15, 1065-1081.

(18) Bard, A. J.; Faulkner, L. R. Electrochemical Methods. Fundamentals and Applications, 2nd ed.; John Wiley \& Sons, Inc.: New York, 2001; p 833.

(19) Morisaki, H.; Ono, H.; Yazawa, K. Measurement of the Density of Electronic States in Aqueous Electrolytes Using Oxide-Covered PtSilicide Electrodes. J. Electrochem. Soc. 1988, 135, 381-383.

(20) Morisaki, H.; Ono, H.; Yazawa, K. Electronic State Densities of Aquo-Complex Ions in Water Determined by Electrochemical Tunneling Spectroscopy. J. Electrochem. Soc. 1989, 136, 1710-1714.

(21) Miller, C.; Cuendet, P.; Graetzel, M. Adsorbed $\omega$-Hydroxy Thiol Monolayers on Gold Electrodes: Evidence for Electron Tunneling to Redox Species in Solution. J. Phys. Chem. 1991, 95, 877-886.

(22) Miller, C.; Graetzel, M. Electrochemistry at $\omega$-Hydroxy Thiol Coated Electrodes. 2. Measurement of the Density of Electronic States Distributions for Several Outer-Sphere Redox Couples. J. Phys. Chem. 1991, 95, 5225-5233.

(23) Wilt, J.; Gong, Y.; Gong, M.; Su, F.; Xu, H.; Sakidja, R.; Elliot, A.; Lu, R.; Zhao, S.; Han, S.; Wu, J. Z. Atomically Thin $\mathrm{Al}_{2} \mathrm{O}_{3}$ Films for Tunnel Junctions. Phys. Rev. Appl. 2017, 7, No. 064022.

(24) Britnell, L.; Gorbachev, R. V.; Jalil, R.; Belle, B. D.; Schedin, F.; Katsnelson, M. I.; Eaves, L.; Morozov, S. V.; Mayorov, A. S.; Peres, N. M. R.; Castro Neto, A. H.; Leist, J.; Geim, A. K.; Ponomarenko, L. A.; Novoselov, K. S. Electron Tunneling through Ultrathin Boron Nitride Crystalline Barriers. Nano Lett. 2012, 12, 1707-1710.

(25) Britnell, L.; Gorbachev, R. V.; Jalil, R.; Belle, B. D.; Schedin, F.; Mishchenko, A.; Georgiou, T.; Katsnelson, M. I.; Eaves, L.; Morozov, S. V.; Peres, N. M. R.; Leist, J.; Geim, A. K.; Novoselov, K. S.; Ponomarenko, L. A. Field-Effect Tunneling Transistor Based on Vertical Graphene Heterostructures. Science 2012, 335, 947-950.

(26) Lee, G.-H.; Yu, Y.-J.; Lee, C.; Dean, C.; Shepard, K. L.; Kim, P.; Hone, J. Electron Tunneling through Atomically Flat and Ultrathin Hexagonal Boron Nitride. Appl. Phys. Lett. 2011, 99, 243114.

(27) Amet, F.; Williams, J. R.; Garcia, A. G. F.; Yankowitz, M.; Watanabe, K.; Taniguchi, T.; Goldhaber-Gordon, D. Tunneling Spectroscopy of Graphene-Boron-Nitride Heterostructures. Phys. Rev. B: Condens. Matter Mater. Phys. 2012, 85, No. 073405.

(28) Chandni, U.; Watanabe, K.; Taniguchi, T.; Eisenstein, J. P. Evidence for Defect-Mediated Tunneling in Hexagonal Boron Nitride-Based Junctions. Nano Lett. 2015, 15, 7329-7333. 
(29) Sachs, B.; Wehling, T. O.; Katsnelson, M. I.; Lichtenstein, A. I. Midgap States and Band Gap Modification in Defective Graphene/hBN Heterostructures. Phys. Rev. B: Condens. Matter Mater. Phys. 2016, 94, 224105.

(30) Velický, M.; Bradley, D. F.; Cooper, A. J.; Hill, E. W.; Kinloch, I. A.; Mishchenko, A.; Novoselov, K. S.; Patten, H. V.; Toth, P. S.; Valota, A. T.; Worrall, S. D.; Dryfe, R. A. W. Electron Transfer Kinetics on Mono- and Multilayer Graphene. ACS Nano 2014, 8, 10089-10100.

(31) McCreery, R. L. Advanced Carbon Electrode Materials for Molecular Electrochemistry. Chem. Rev. (Washington, DC, U. S.) 2008, 108, 2646-2687.

(32) Zhang, G.; Cuharuc, A. S.; Güell, A. G.; Unwin, P. R. Electrochemistry at Highly Oriented Pyrolytic Graphite (HOPG): Lower Limit for the Kinetics of Outer-Sphere Redox Processes and General Implications for Electron Transfer Models. Phys. Chem. Chem. Phys. 2015, 17, 11827-11838.

(33) Kretinin, A. V.; Cao, Y.; Tu, J. S.; Yu, G. L.; Jalil, R.; Novoselov, K. S.; Haigh, S. J.; Gholinia, A.; Mishchenko, A.; Lozada, M.; Georgiou, T.; Woods, C. R.; Withers, F.; Blake, P.; Eda, G.; Wirsig, A.; Hucho, C.; Watanabe, K.; Taniguchi, T.; Geim, A. K.; et al. Electronic Properties of Graphene Encapsulated with Different TwoDimensional Atomic Crystals. Nano Lett. 2014, 14, 3270-3276.

(34) Velický, M.; Bissett, M. A.; Toth, P. S.; Patten, H. V.; Worrall, S. D.; Rodgers, A. N. J.; Hill, E. W.; Kinloch, I. A.; Novoselov, K. S.; Georgiou, T.; Britnell, L.; Dryfe, R. A. W. Electron Transfer Kinetics on Natural Crystals of $\mathrm{MoS}_{2}$ and Graphite. Phys. Chem. Chem. Phys. 2015, 17, 17844-17853.

(35) Kneten, K. R; McCreery, R. L. Effects of Redox System Structure on Electron-Transfer Kinetics at Ordered Graphite and Glassy Carbon Electrodes. Anal. Chem. 1992, 64, 2518-2524.

(36) Velický, M.; Toth, P. S.; Woods, C. R.; Novoselov, K. S.; Dryfe, R. A. W. Electrochemistry of the Basal Plane versus Edge Plane of Graphite Revisited. J. Phys. Chem. C 2019, 123, 11677-11685.

(37) Smalley, J. F.; Feldberg, S. W.; Chidsey, C. E. D.; Linford, M. R.; Newton, M. D.; Liu, Y.-P. The Kinetics of Electron Transfer through Ferrocene-Terminated Alkanethiol Monolayers on Gold. J. Phys. Chem. 1995, 99, 13141-13149.

(38) Smalley, J. F.; Finklea, H. O.; Chidsey, C. E. D.; Linford, M. R.; Creager, S. E.; Ferraris, J. P.; Chalfant, K.; Zawodzinsk, T.; Feldberg, S. W.; Newton, M. D. Heterogeneous Electron-Transfer Kinetics for Ruthenium and Ferrocene Redox Moieties through Alkanethiol Monolayers on Gold. J. Am. Chem. Soc. 2003, 125, 2004-2013.

(39) Creager, S.; Yu, C. J.; Bamdad, C.; O’Connor, S.; MacLean, T.; Lam, E.; Chong, Y.; Olsen, G. T.; Luo, J.; Gozin, M.; Kayyem, J. F. Electron Transfer at Electrodes through Conjugated "Molecular Wire" Bridges. J. Am. Chem. Soc. 1999, 121, 1059-1064.

(40) Sachs, S. B.; Dudek, S. P.; Hsung, R. P.; Sita, L. R.; Smalley, J. F.; Newton, M. D.; Feldberg, S. W.; Chidsey, C. E. D. Rates of Interfacial Electron Transfer through $\pi$-Conjugated Spacers. J. Am. Chem. Soc. 1997, 119, 10563-10564.

(41) Bergren, A. J.; McCreery, R. L.; Stoyanov, S. R.; Gusarov, S.; Kovalenko, A. Electronic Characteristics and Charge Transport Mechanisms for Large Area Aromatic Molecular Junctions. J. Phys. Chem. C 2010, 114, 15806-15815.

(42) Ru, J.; Szeto, B.; Bonifas, A.; McCreery, R. L. Microfabrication and Integration of Diazonium-Based Aromatic Molecular Junctions. ACS Appl. Mater. Interfaces 2010, 2, 3693-3701.

(43) Yan, H.; Bergren, A. J.; McCreery, R. L. All-Carbon Molecular Tunnel Junctions. J. Am. Chem. Soc. 2011, 133, 19168-19177.

(44) Feldberg, S. W.; Sutin, N. Distance Dependence of Heterogeneous Electron Transfer through the Nonadiabatic and Adiabatic Regimes. Chem. Phys. 2006, 324, 216-225.

(45) Swaddle, T. W. Homogeneous versus Heterogeneous SelfExchange Electron Transfer Reactions of Metal Complexes: Insights from Pressure Effects. Chem. Rev. (Washington, DC, U. S.) 2005, 105, $2573-2608$.
(46) Weaver, M. J. Dynamical Solvent Effects on Activated ElectronTransfer Reactions: Principles, Pitfalls, and Progress. Chem. Rev. (Washington, DC, U. S.) 1992, 92, 463-480.

(47) Mikkelsen, K. V.; Ratner, M. A. Electron Tunneling in SolidState Electron-Transfer Reactions. Chem. Rev. (Washington, DC, U. S.) 1987, 87, 113-153.

(48) Sutin, N. Nuclear, Electronic, and Frequency Factors in Electron Transfer Reactions. Acc. Chem. Res. 1982, 15, 275-282.

(49) Gerischer, H. An Interpretation of the Double Layer Capacity of Graphite Electrodes in Relation to the Density of States at the Fermi Level. J. Phys. Chem. 1985, 89, 4249-4251.

(50) Royea, W. J.; Hamann, T. W.; Brunschwig, B. S.; Lewis, N. S. A Comparison between Interfacial Electron-Transfer Rate Constants at Metallic and Graphite Electrodes. J. Phys. Chem. B 2006, 110, 1943319442 .

(51) Sun, P.; Mirkin, M. V. Kinetics of Electron-Transfer Reactions at Nanoelectrodes. Anal. Chem. 2006, 78, 6526-6534.

(52) Slowinski, K.; Slowinska, K. U.; Majda, M. Electron Tunneling across Hexadecanethiolate Monolayers on Mercury Electrodes: Reorganization Energy, Structure, and Permeability of the Alkane/ Water Interface. J. Phys. Chem. B 1999, 103, 8544-8551.

(53) Henck, H.; Pierucci, D.; Fugallo, G.; Avila, J.; Cassabois, G.; Dappe, Y. J.; Silly, M. G.; Chen, C.; Gil, B.; Gatti, M.; Sottile, F.; Sirotti, F.; Asensio, M. C.; Ouerghi, A. Direct Observation of the Band Structure in Bulk Hexagonal Boron Nitride. Phys. Rev. B: Condens. Matter Mater. Phys. 2017, 95, No. 085410.

(54) Trasatti, S. The Absolute Electrode Potential: An Explanatory Note (Recommendations 1986). J. Electroanal. Chem. Interfacial Electrochem. 1986, 209, 417-428.

(55) Taniguchi, T.; Watanabe, K. Synthesis of High-Purity Boron Nitride Single Crystals under High Pressure by Using Ba-BN Solvent. J. Cryst. Growth 2007, 303, 525-529.

(56) Gibb, A. L.; Alem, N.; Chen, J.-H.; Erickson, K. J.; Ciston, J.; Gautam, A.; Linck, M.; Zettl, A. Atomic Resolution Imaging of Grain Boundary Defects in Monolayer Chemical Vapor Deposition-Grown Hexagonal Boron Nitride. J. Am. Chem. Soc. 2013, 135, 6758-6761.

(57) Velický, M.; Donnelly, G. E.; Hendren, W. R.; McFarland, S.; Scullion, D.; DeBenedetti, W. J. I.; Correa, G. C.; Han, Y.; Wain, A. J.; Hines, M. A.; Muller, D. A.; Novoselov, K. S.; Abruña, H. D.; Bowman, R. M.; Santos, E. J. G.; Huang, F. Mechanism of GoldAssisted Exfoliation of Centimeter-Sized Transition-Metal Dichalcogenide Monolayers. ACS Nano 2018, 12, 10463-10472.

(58) Uosaki, K.; Elumalai, G.; Noguchi, H.; Masuda, T.; Lyalin, A.; Nakayama, A.; Taketsugu, T. Boron Nitride Nanosheet on Gold as an Electrocatalyst for Oxygen Reduction Reaction: Theoretical Suggestion and Experimental Proof. J. Am. Chem. Soc. 2014, 136, 65426545.

(59) Liu, D.-Q.; Tao, B.; Ruan, H.-C.; Bentley, C. L.; Unwin, P. R. Metal Support Effects in Electrocatalysis at Hexagonal Boron Nitride. Chem. Commun. (Cambridge, U. K.) 2019, 55, 628-631.

(60) Hu, S.; Lozada-Hidalgo, M.; Wang, F. C.; Mishchenko, A.; Schedin, F.; Nair, R. R.; Hill, E. W.; Boukhvalov, D. W.; Katsnelson, M. I.; Dryfe, R. A. W.; Grigorieva, I. V.; Wu, H. A.; Geim, A. K. Proton Transport through One-Atom-Thick Crystals. Nature 2014, $516,227-230$

(61) Wang, L.; Xu, X.; Zhang, L.; Qiao, R.; Wu, M.; Wang, Z.; Zhang, S.; Liang, J.; Zhang, Z.; Zhang, Z.; Chen, W.; Xie, X.; Zong, J.; Shan, Y.; Guo, Y.; Willinger, M.; Wu, H.; Li, Q.; Wang, W.; Gao, P.; et al. Epitaxial Growth of a 100-Square-Centimetre Single-Crystal Hexagonal Boron Nitride Monolayer on Copper. Nature 2019, 570, $91-95$.

(62) Wang, L.; Meric, I.; Huang, P. Y.; Gao, Q.; Gao, Y.; Tran, H.; Taniguchi, T.; Watanabe, K.; Campos, L. M.; Muller, D. A.; Guo, J.; Kim, P.; Hone, J.; Shepard, K. L.; Dean, C. R. One-Dimensional Electrical Contact to a Two-Dimensional Material. Science 2013, 342, 614-617.

(63) Velický, M.; Bissett, M. A.; Woods, C. R.; Toth, P. S.; Georgiou, T.; Kinloch, I. A.; Novoselov, K. S.; Dryfe, R. A. W. 
Photoelectrochemistry of Pristine Mono- and Few-Layer $\mathrm{MoS}_{2}$. Nano Lett. 2016, 16, 2023-2032.

(64) Oldham, K. B.; Zoski, C. G. Comparison of Voltammetric Steady States at Hemispherical and Disc Microelectrodes. J. Electroanal. Chem. Interfacial Electrochem. 1988, 256, 11-19.

(65) Kresse, G.; Furthmüller, J. Efficient Iterative Schemes for $A b$ Initio Total-Energy Calculations Using a Plane-Wave Basis Set. Phys. Rev. B: Condens. Matter Mater. Phys. 1996, 54, 11169-11186.

(66) Hinuma, Y.; Grüneis, A.; Kresse, G.; Oba, F. Band Alignment of Semiconductors from Density-Functional Theory and Many-Body Perturbation Theory. Phys. Rev. B: Condens. Matter Mater. Phys. 2014, 90, 155405.

(67) Heyd, J.; Scuseria, G. E.; Ernzerhof, M. Erratum: "Hybrid Functionals Based on a Screened Coulomb Potential" [J. Chem. Phys. 118, 8207 (2003)]. J. Chem. Phys. 2006, 124, 219906. 